\title{
Treatment of Chronic Wounds With the Silver-Containing Activated Carbon Fiber Dressing: Three Cases
}

\author{
Chun-Hao Tsai ${ }^{\mathrm{a}, \mathrm{b}}$, Horng-Chaung Hsu ${ }^{\mathrm{a}}$, Cheng-Jyh Lin ${ }^{\mathrm{a}, \mathrm{c}}$
}

\begin{abstract}
Instead of simply covering and concealing wounds, it is necessary to choose adequate wound dressings to provide proper conditions for wound healing. Silver has long been used clinically throughout the history because of having potent and broad-acting antiseptic properties. Various types of silver-containing wound dressings are commercially available, including activated carbon fiber (ACF)-based silver dressings. ACF possesses two unique and well-known characteristics: a tremendous adsorptive capacity owing to a great network of submicroscopic pores on the surface, and the capability of far-infrared ray emission. Here, we presented three patients with entirely different background. All of them had a chronic wound lasting for several months or years. After they switched the treatment to the silver-containing ACF dressing, their wounds healed in 3 months without any adverse reaction. A randomized controlled trial is merited to test efficacy of this dressing against a recognized standard of care dressing in formerly non-healing wounds.
\end{abstract}

Keywords: Activated carbon fiber; Silver-containing dressing; Chronic wound

\section{Introduction}

Chronic wounds, the major healthcare problem, were the wounds that have been stuck in any one of the wound healing phases (hemostasis, inflammation, proliferation, and remodeling) for a period of 6 weeks or more $[1,2]$, and usually exhibit phenomena such as existence of necrotic tissues, lack of healthy granulation tissues, incomplete remodeling of extracellular matrix, incapability of epithelialization, and an

Manuscript accepted for publication September 25, 2014

aDepartment of Orthopaedics, China Medical University Hospital, Taichung, Taiwan

${ }^{\mathrm{b}}$ Graduate Institute of Medicine, China Medical University, Taichung, Taiwan ${ }^{\mathrm{c} C o r r e s p o n d i n g ~ A u t h o r: ~ C h e n g-J y h ~ L i n, ~ D e p a r t m e n t ~ o f ~ O r t h o p a e d i c s, ~ C h i n a ~}$ Medical University Hospital, 2 Yude Rd., Taichung 40447, Taiwan.

Email: kingsunchou@gmail.com

doi: http://dx.doi.org/10.14740/jmc1960w interruption in wound improvement [1, 3, 4]. Many factors, including personal health condition (e.g., diabetes, cardiovascular defects, hepatic diseases, immunodeficiency, aging, cancers, etc.) and wound infection, make wound healing progress languishing and lead to the formation of chronic wounds $[5,6]$.

Controlling the microbial bioburden and all other variables involved in delaying healing of a specific wound is crucial to improve healing $[7,8]$. Local or systemic administration of antibiotics is often the major option of conventional treatment. However, it is not suitable for patients with specific conditions like allergy to antibiotics or poor circulation. Furthermore, the use of antibiotics would result in generation of drug-resistant bacteria, increasing the difficulty of wound care. Silver has been utilized as medication for more than 2,000 years $[9,10]$. The antimicrobial activity of silver ion is achieved via binding to bacterial proteins, causing alterations of their structure which in turn block protein synthesis, cellular respiratory, electron transport chain, and destroy bacterial cell membranes. Moreover, silver ions bind to bacterial deoxyribonucleic acid or ribonucleic acid, thereby inhibiting genome replication, transcription and cell division, and ultimately inducing cell death $[3,9,11-16]$. Due to these multiple antimicrobial mechanisms, the possibility to generate silver-resistant bacteria is very low $[5,17]$. Though silver's capacity to promote wound

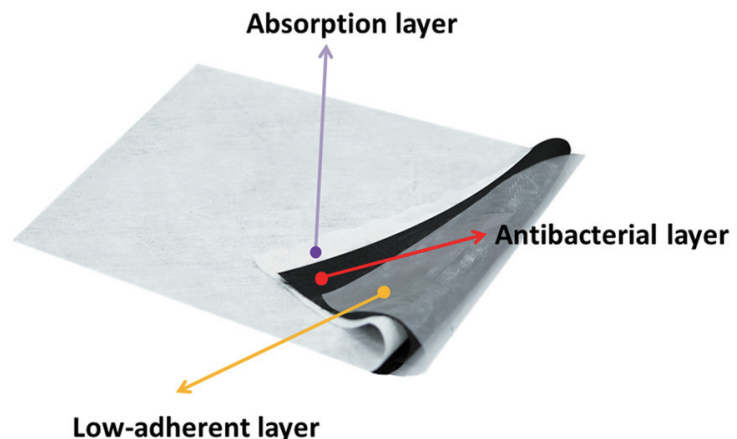

Figure 1. The three-layer structure diagram of KoCarbonAg ${ }^{\circledR}(\mathrm{Ag} /$ ACF). The upper absorption layer (PET non-woven) helps exudate absorption. The bottom low-adherent layer (polyethylene film) minimizes adherence to the wound bed. The middle antibacterial layer, composed of silver-containing ACF, is where the major absorption and FIR emission take place. 


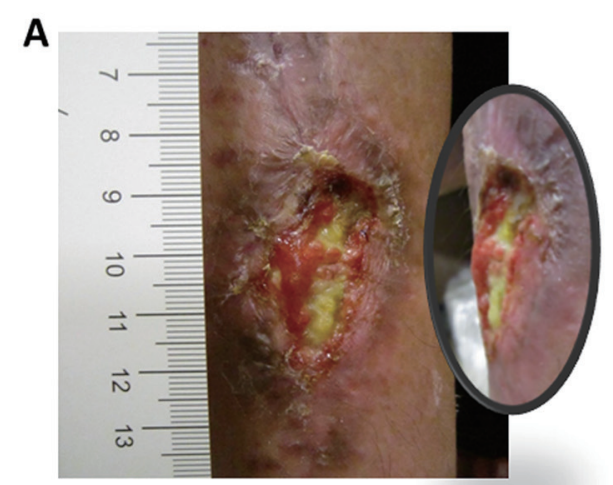

B

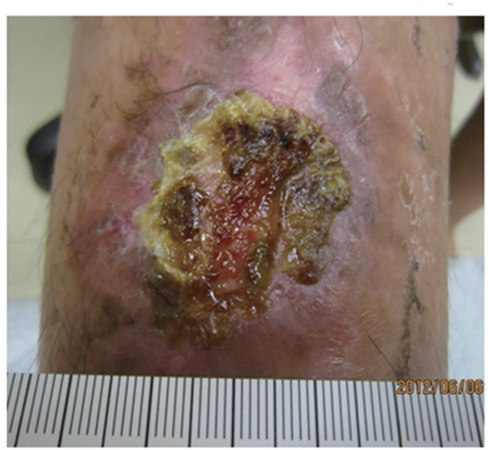

C

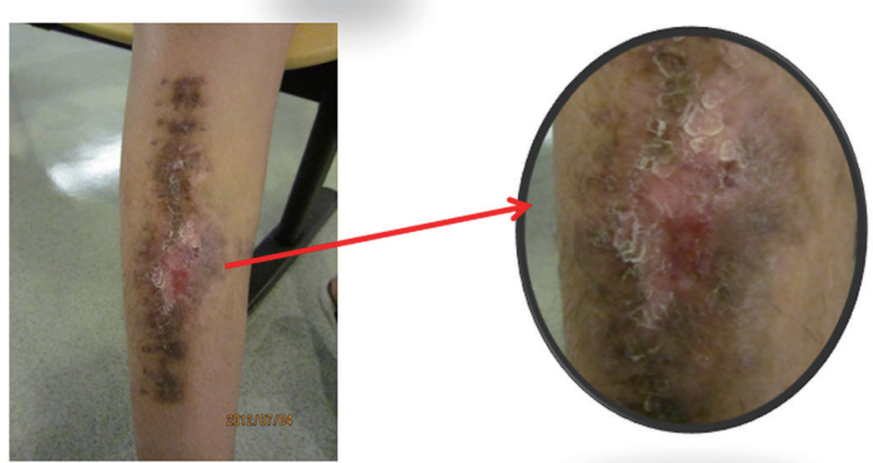

Figure 2. Case 1: the post operation wound. (A) The wound was $3.5 \times 2.5 \mathrm{~cm}$, located at the front side of left lower leg, consisted of $60 \%$ granulation tissue and $40 \%$ slough, and was detained for more than 3 months. The smaller oval-shaped figure: lateral view. (B) The photo on day 28. (C) The photo on day 56. The smaller oval-shaped figure: magnified view.

healing in clinical wounds remains controversial $[18,19]$, its broad-spectrum antibacterial activity still attracts attentions for a variety of biomedical applications, including wound care products.

Currently, there are various forms of commercial silvercontaining dressings, such as foams, hydrocolloids, hydrogels, meshes, or alginate [5], and the material used could determine the property of the dressing. Activated carbon fiber (ACF) has excellent adsorptive capacity for chemicals and gases due to its high degree of microporosity and enormous internal surface area [20]. KoCarbon $\mathrm{Ag}^{\circledR}$, a commercial silver-containing ACF-based dressing (Ag/ACF), comprises a three-layer structure: an absorption layer, an low-adherent layer and an antibacterial layer, made of polyethylene terephthalate (PET) non-woven, polyethylene film and silver-impregnated ACF, respectively (Fig. 1). In this study, we present three clinical cases with chronic wounds healed after Ag/ACF treatment. No adverse reaction of the $\mathrm{Ag} / \mathrm{ACF}$ was reported during the treatment. These data demonstrated that use of this $\mathrm{Ag} / \mathrm{ACF}$ dressing was associated with healing progression of challenging wounds.

\section{Case Reports}

\section{Case 1}

The patient was a 12-year-old female without any chronic or hereditary diseases such as diabetes mellitus (DM) and congenital skin disorder. She had a crushing injury over her right leg associated with tibia-fibular shaft fracture from a car accident. Open reduction and intramadular nail internal fixation with surgery were performed, and the wound at anterior leg was initially treated with traditional wet gauze. However, the wound had failed to heal after more than 3 months. Before the intervention treatment of $\mathrm{Ag} / \mathrm{ACF}$ began, the wound size was $3.5 \times 2.5 \mathrm{~cm}$, and it showed moderate light-yellow exudate but no obvious signs of inflammation and infection (Fig. 2A). The granulation tissue and slough in the wound were about $60 \%$ and $40 \%$ respectively (Fig. 2A). After debridement to remove the superficial eschar around the wound, the Ag/ACF dressing was applied by facing the black-colored side toward the wound surface, and gauzes were used as a secondary dressing to assist in absorbing exudate. The dressings were changed every 2 days. After 28 days of $\mathrm{Ag} / \mathrm{ACF}$ treatment, the wound size was reduced to $2.5 \times 1 \mathrm{~cm}$. In addition, the wound was filled with granulation tissue, and tiny eschar formation was observed at the wound's edge (Fig. 2B). The frequency of dressing changes was decreased to once every 3 days since then. After another 28 days, the wound was almost epithelialized completely (Fig. 2C).

\section{Case 2}

A 92-year-old female patient was long-term bedridden due to paralysis, and had a big grade IV pressure ulcer at pars sa- 

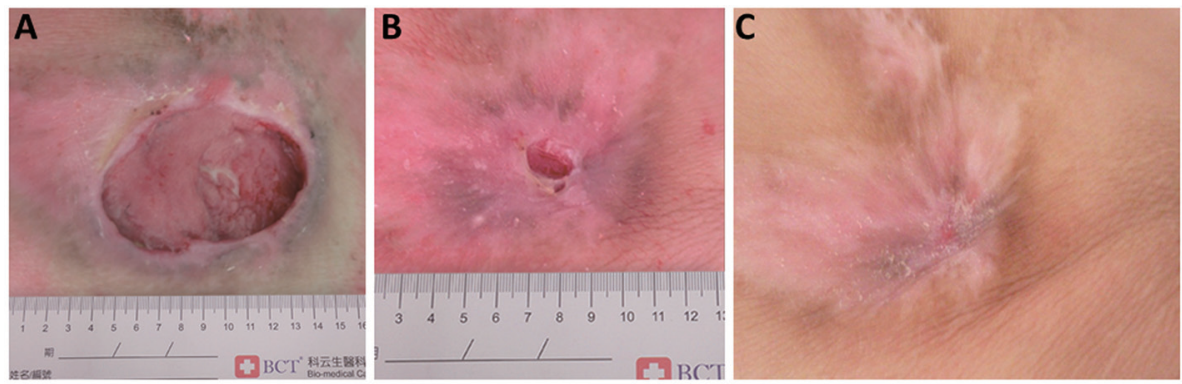

Figure 3. Case 2: a pressure ulcer. (A) A grade IV pressure ulcer located at pars sacralis with Acinetobacter baumanii infection. The wound size was $10 \times 5 \times 3 \mathrm{~cm}$ with pus and odor before using Ag/ACF. (B) The photo on day 60. (C) The photo on day 100 .

cralis. The wound was managed with wet gauze, and debridement surgery was performed over and over because necrosis occurred constantly. Later, systemic antibiotics were administered against Acinetobacter baumanii infection but failed. Just before $\mathrm{Ag} / \mathrm{ACF}$ application, the wound size was $10 \times 5 \times 3 \mathrm{~cm}$ with pus and odor (Fig. 3A). The Ag/ACF dressings were used and changed every 2 or 3 days. After 7 days, the infection was significantly controlled. The granulation tissues kept growing during the $\mathrm{Ag} / \mathrm{ACF}$ dressing treatment. The wound reduced to $1.5 \times 1.5 \times 0.5 \mathrm{~cm}$ after 60 days (Fig. 3B), and completely healed after 100 days (Fig. 3C).

\section{Case 3}

The patient was a 59-year-old male with DM and poor circulation of lower limbs. A $10 \times 10 \mathrm{~cm}$ ulcer on his calf was treated with traditional Chinese herbal medicine for more than 1 year. However, the wound was getting worse, becoming swollen, festering, bleeding, and smelly (Fig. 4A). After slightly debrided, the wound was covered with the $\mathrm{Ag} / \mathrm{ACF}$ dressing, which was changed twice a week. By day 16, the wound showed positive signs including the reduction of the malodor and pus (Fig. 4B). The evidence of healing continued, and by day 32 , the epithelialization process was finished and the wound completely healed (Fig. 4C).

\section{Discussion}

Due to the special arrangement of carbon atom, the carbon- based material exposed to certain activation process (usually with controlled high atmosphere and high temperature) would gain a network of submicroscopic pores on the surface. The highly porous nature and a large specific surface area of the activated carbon provide a tremendous absorptive capacity for many compounds, and so called "activated". Activated carbon has been applied in wound dressings to control would malodor [20]. ACF is the carbon-based fiber cloths with larger degree of microporosity than traditional activated carbon, making the ACF possess a better absorption efficiency, and allow less frequent dressing changes as the wound progressed to healing. Although the great absorption ability is a common feature of many commercial dressing products, the deodorization effect of ACF makes it able to manage malodorous wounds [21, 22], and improve the patient's life quality.

Compared to other commercially available silver-containing dressings, this Ag/ACF dressing exhibited lower cytotoxicity to fibroblasts and similar antibacterial activities in vitro, and promoted in vivo wound healing in a greater degree $[20,23]$. Another similar dressing product, which comprises silver impregnated charcoal activated carbon cloth enclosed in a sleeve of non-woven nylon, also presented an ability to remove bacteria from wound exudate [13], and a high in vitro endotoxin-binding capacity [24]. Besides the huge adsorptive capacity for micro-organisms, toxins, wound degradation byproducts, and odors, ACF has a remarkable advantage which all the other dressings lack - stable emission of far-infrared ray (FIR) [25], which has been proven to promote wound healing possibly by stimulating the secretion of transforming growth factor $\beta 1$, the migration of fibroblasts, or the production of collagen fibers due to the activation of fibroblasts [26]. Although
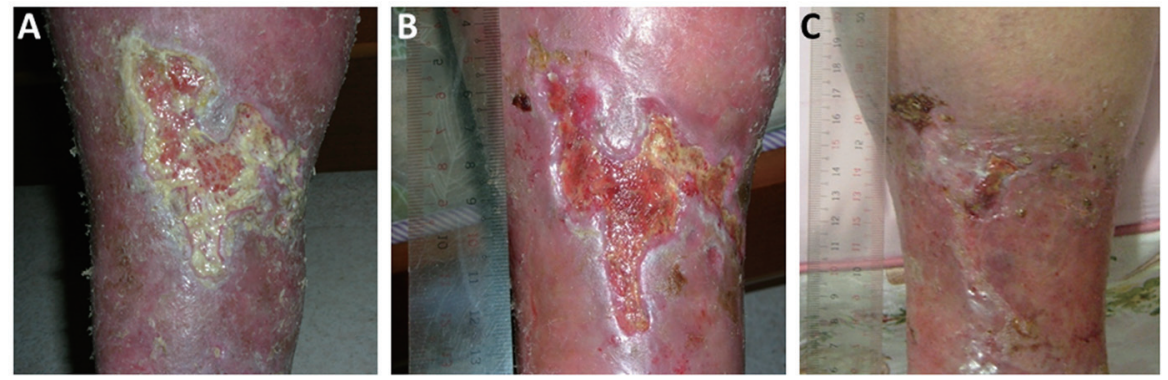

Figure 4. Case 3. (A) A $10 \times 10 \mathrm{~cm}$ leg ulcer was located on the calf with hemorrhage and malodor before the intervention of Ag/ ACF. The yellow cream was the traditional Chinese herbal medicine. (B) The photo on day 16. (C) The photo on day 32. 
with lower energy and weaker penetration ability, FIR can elevate skin's surface temperature gently that hardly causes adverse inflammatory reactions and burns, and transmit energy to deep tissues via resonance effects. In fact, FIR has already been broadly applied to daily health care and clinical wound treatment as it is safe and beneficial to biological functions.

Wound healing is a subtle and complex process involving various factors, such as the basal health condition and the life style of individuals. The first case is young and healthy, without any records of chronic or hereditary diseases. She does not smoke and drink, and lives a regular life. Her wound showed no signs of infection; however, it did not get better after traditional treatment for more than 3 months. It is speculated that she might carry special physiological conditions which need further examinations to find out. All wounds showed here were originally cared by traditional way for several months to years. During the usage of the $\mathrm{Ag} / \mathrm{ACF}$ dressing, the silver ions released to the wound bed, together with the ACF, may create an environment suitable for granulation and epithelialization, and made the wound completely healed within 3 months. In conclusion, the $\mathrm{Ag} / \mathrm{ACF}$ dressing improved the healing of challenging chronic wounds, such as the pressure ulcer and the $\mathrm{DM}$ leg ulcer. A randomized controlled trial is arranged to test efficacy of the $\mathrm{Ag} / \mathrm{ACF}$ dressing against a recognized standard of care dressing in formerly non-healing wounds.

\section{Grant Support}

Authors were not supported by any grant.

\section{Conflict of Interest}

Authors declare no conflict of interest.

\section{References}

1. Collier M. Wound bed preparation: theory to practice. Nurs Stand. 2003;17(36):45-52; quiz 54-45.

2. Lo SF, Hayter M, Chang CJ, Hu WY, Lee LL. A systematic review of silver-releasing dressings in the management of infected chronic wounds. J Clin Nurs. 2008;17(15):19731985.

3. Fong J, Wood F. Nanocrystalline silver dressings in wound management: a review. Int $\mathrm{J}$ Nanomedicine. 2006;1(4):441-449.

4. Landis SJ. Chronic wound infection and antimicrobial use. Adv Skin Wound Care. 2008;21(11):531-540; quiz 541-532.

5. Toy LW, Macera L. Evidence-based review of silver dressing use on chronic wounds. J Am Acad Nurse Pract. 2011;23(4):183-192.

6. Fonder MA, Lazarus GS, Cowan DA, Aronson-Cook B, Kohli AR, Mamelak AJ. Treating the chronic wound: A practical approach to the care of nonhealing wounds and wound care dressings. J Am Acad Dermatol.
2008;58(2):185-206.

7. Schultz GS, Barillo DJ, Mozingo DW, Chin GA. Wound bed preparation and a brief history of TIME. Int Wound J. 2004;1(1):19-32.

8. Sibbald RG, Orsted H, Schultz GS, Coutts P, Keast D. Preparing the wound bed 2003: focus on infection and inflammation. Ostomy Wound Manage. 2003;49(11):24-51.

9. Chaloupka K, Malam Y, Seifalian AM. Nanosilver as a new generation of nanoproduct in biomedical applications. Trends Biotechnol. 2010;28(11):580-588.

10. Khundkar R, Malic C, Burge T. Use of Acticoat dressings in burns: what is the evidence? Burns. 2010;36(6):751758.

11. Dunn K, Edwards-Jones V. The role of Acticoat with nanocrystalline silver in the management of burns. Burns. 2004;30(Suppl 1):S1-9.

12. Lansdown AB. Silver. I: Its antibacterial properties and mechanism of action. J Wound Care. 2002;11(4):125130.

13. Thomas S, McCubbin P. A comparison of the antimicrobial effects of four silver-containing dressings on three organisms. J Wound Care. 2003;12(3):101-107.

14. Thomas S, McCubbin P. An in vitro analysis of the antimicrobial properties of 10 silver-containing dressings. J Wound Care. 2003;12(8):305-308.

15. Tredget EE, Shankowsky HA, Groeneveld A, Burrell R. A matched-pair, randomized study evaluating the efficacy and safety of Acticoat silver-coated dressing for the treatment of burn wounds. J Burn Care Rehabil. 1998;19(6):531-537.

16. Yin HQ, Langford R, Burrell RE. Comparative evaluation of the antimicrobial activity of ACTICOAT antimicrobial barrier dressing. J Burn Care Rehabil. 1999;20(3):195200.

17. Warriner R, Burrell R. Infection and the chronic wound: a focus on silver. Adv Skin Wound Care. 2005;18(Suppl 1):2-12.

18. Bergin SM, Wraight P. Silver based wound dressings and topical agents for treating diabetic foot ulcers. Cochrane Database Syst Rev. 2006;(1):CD005082.

19. Innes ME, Umraw N, Fish JS, Gomez M, Cartotto RC. The use of silver coated dressings on donor site wounds: a prospective, controlled matched pair study. Burns. 2001;27(6):621-627.

20. Lin YH, Hsu WS, Chung WY, Ko TH, Lin JH. Evaluation of various silver-containing dressing on infected excision wound healing study. J Mater Sci Mater Med. 2014;25(5):1375-1386.

21. Hampton S. Malodorous fungating wounds: how dressings alleviate symptoms. Br J Community Nurs. 2008;13(6):S31-32, S34, S36 passim.

22. Sornakumar L, Kalarani M, Srinivas CR. Activated charcoal dressing in malodorous leg ulcers. Indian J Lepr. 2010;82(3):147-148.

23. Lin YH, Lin JH, Wang SH, Ko TH, Tseng GC. Evaluation of silver-containing activated carbon fiber for wound healing study: In vitro and in vivo. J Biomed Mater Res B Appl Biomater. 2012;100(8):2288-2296. 
24. Muller G, Winkler Y, Kramer A. Antibacterial activity and endotoxin-binding capacity of Actisorb Silver 220. J Hosp Infect. 2003;53(3):211-214.

25. Teraoka F, Hamada Y, Takahashi J. Bamboo charcoal inhibits growth of HeLa cells in vitro. Dent Mater J.
2004;23(4):633-637.

26. Toyokawa H, Matsui Y, Uhara J, Tsuchiya H, Teshima S, Nakanishi H, Kwon AH, et al. Promotive effects of farinfrared ray on full-thickness skin wound healing in rats. Exp Biol Med (Maywood). 2003;228(6):724-729. 